\title{
Comprehensive Compensation Method for Harmonics and Negative Sequence Current in High-speed Railway under Grid Voltage Distortion
}

\author{
Mingxing Tian, Yuqi Zhou and Hong Yan \\ School of Automation \& Electrical Engineering, Lanzhou Jiaotong University \\ Lanzhou Jiaotong University, Lanzhou, Gansu, 730070, China. \\ zhou123yuqi@126.com
}

\begin{abstract}
As the grid voltage of the V/v power supply system for high-speed railway is distorted, the detection method for harmonic and negative sequence current is complex, and there are errors in the detection result. A method is proposed in order to solve these issues, which is capable of carrying out fast and accurately comprehensive compensation for grid current without the PLL circuit. During the detection process, a group of sine and cosine function with arbitrary initial phase angle is needed, the grid fundamental positive sequence voltage is extracted to participate into the detection of fundamental active power component to obtain the command signal. The calculation process is fast and simple and not affected by the distorted grid voltage. The correctness and feasibility of this method is verified by the result of simulation
\end{abstract}

Keywords: high-speed railway, harmonic detection, simulation

\section{Introduction}

As the national power system is developing increasingly fast, the requirement of users for power quality is becoming more and more high, electrified railway's influence on the power system has been paid more and more attention[1-2]. Since most electric locomotives are single-phase rectifier load, random fluctuations are frequent, large amounts of harmonic and negative sequence current produced by the electric traction power supply system are injected into the power grid. As a result, the grid voltage and current are asymmetrical and the harmonic content is increased, which lead to a series of problems including the overheat of motor rotor in power plant, the service life of transformer is shorten, the misoperation of relay protection device and so on, these issues have a great influence on the safe and stable operation of power system[3-5].

Since there are large amounts of reactive power, harmonics and negative sequence current in the electric traction power supply system, domestic and foreign scholars have conducted extensive studies on these issues[6-10]. Literature[8-10] proposed methods for detecting command current and comprehensive compensation method under the balanced transformer power supply pattern, comprehensive compensation principles and treatment methods for harmonics and negative sequence current in electrified railway were analyzed while $\mathrm{Y} />/ \mathrm{D}$ transformers, Scott transformers, impedance matching transformers were used as traction transformer. But the detection for compensation current needs not only phase-locked loop but also a series of matrix operation such as phase sequence structure, $3 / 2$ conversion and so on, as a result, the complexity of the detecting process is increased. 
In literature [11-16], compensation principle and comprehensive compensation schemes of the power regulator in different topologies under the high-speed railway V/v transformer power supply pattern were analyzed and studied respectively. In literature [15-16], a simplified new high-speed railway compensation device based on half-bridge structure and two-phase three-wire converter were proposed respectively, the capacity of the active part was reduced while the reliability of the compensation device was improved. It's not difficult to see that the detection method for command signal based on phase identifying principle was generally used in literature[11-16], the error caused by the PLL circuit in the detection process leads to not only calculation error of active current but also affect the result of comprehensive compensation for negative sequence and harmonic.

The literatures above are all about the treatment method for harmonic and negative sequence current in railway power regulator when the power grid voltage are ideal, however, there are few literatures focus on improving the method for improving the power quality of electrified railway under the condition that the grid voltage is distorted in the current highspeed railway V/v traction power supply system.

In this paper, a method for extracting fundamental positive sequence voltage from threephase grid without PLL circuit is proposed based on the analysis of high speed railway V/V transformer power supply pattern, this method applies the principle of active power conservation of the transformer primary side and secondary side, and then converts it into the command signal for comprehensive compensation of harmonics and negative sequence current of the two power arms by detecting the fundamental active component in the grid current, which makes the three-phase current in the grid symmetrical and eliminates the influence of distorted grid voltage on the detection of harmonic and negative current. Simulation results verify the correctness and feasibility of this detection method.

\section{Topology and Working Principle of Power Regulator}

\subsection{Topology of Power Regulator}

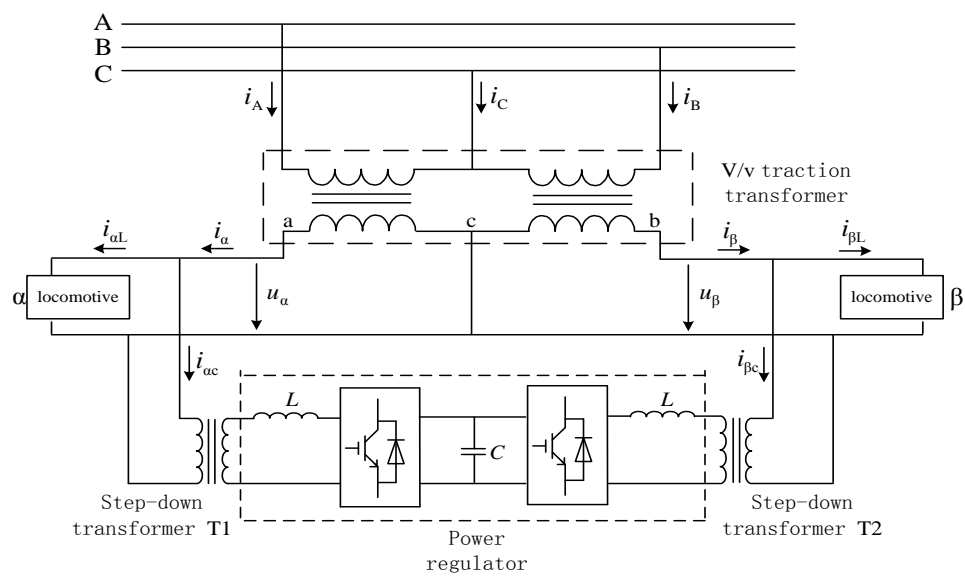

Figure 1. Topology Structure of Power Conditioner

The topology of high-speed railway power regulator is shown in figure 1. The three-phase $220 \mathrm{kV}$ high voltage $U_{\mathrm{A}}, U_{\mathrm{B}}, U_{\mathrm{C}}$ are converted into two-phase voltage $U_{\alpha}, U_{\beta}$ by the $\mathrm{V} / \mathrm{v}$ traction transformer to supply power to the two supply arms. Railway power regulator is connected to the two supply arms by a group of single-phase inverter through output inductor 
$\mathrm{L}$ and step-down transformer, a common capacitor is used on the DC side of the two inverters to provide a stable DC voltage. By controlling the power regulator, we can effectively compensate harmonic and reactive current of the two arms and provide flowing access for active current component of the two arms, meanwhile, the secondary current of $\mathrm{V} / \mathrm{v}$ transformer will be maintained balanced and the grid current will be three-phase symmetrical.

\subsection{Working Principle of Power Regulator}

Due to the electric locomotive of high-speed railway presents randomly, current size of the two supply arms changes, as a result, negative sequence current is injected into the power system and leads to severe asymmetry of the grid current. Power regulator eliminates the effect of harmonics, reactive and negative sequence current on the power system by real-time detection and compensation for the current of the two supply arms, by which the current size of the two phases are kept equal and in phase with the grid current. According to the wiring form of $\mathrm{V} / \mathrm{v}$ transformer, the relationship of $\mathrm{V} / \mathrm{v}$ transformer primary and secondary side current is proposed as

$$
\left\{\begin{array}{l}
\dot{I}_{\mathrm{A}}=\frac{1}{k} \dot{I}_{\alpha}=\frac{1}{k} I_{\alpha \mathrm{Lf}} e^{-\mathrm{j} 30^{\circ}} \\
\dot{I}_{\mathrm{B}}=\frac{1}{k} \dot{I}_{\beta}=\frac{1}{k} I_{\beta \mathrm{Lf}} e^{-\mathrm{j} 90^{\circ}} \\
\dot{I}_{\mathrm{C}}=-\left(\dot{I}_{\mathrm{A}}+\dot{I}_{\mathrm{B}}\right)
\end{array}\right.
$$

Where $k$ is $\mathrm{V} / \mathrm{v}$ transformer ratio.

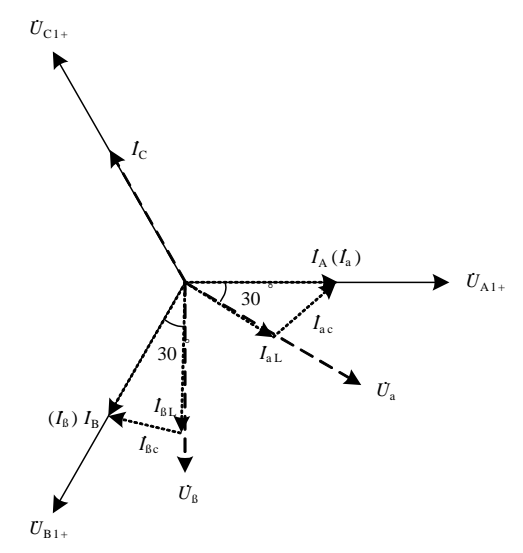

Figure 2. Phasor Graph of Comprehensive Compensation for Current

As the condition that the grid voltage is distorted, this paper proposed a new method for comprehensive compensation of power regulator in high-speed railway, as shown in figure 2. In order to maintain the $\mathrm{ABC}$ three phase current symmetrical, power regulator

compensates current $I_{\alpha c}, I_{\beta c}$ respectively by detecting fundamental positive sequence voltage of the grid, in a word, it can keep the three phase current in the grid symmetrical and be in phase with the grid fundamental voltage. 


\section{Detection of Grid Fundamental Positive Sequence Voltage}

Because of the effect of power system transmission line impedance, the existence of large amounts of harmonics and reactive current leads to the pollution of power quality at common connection point of the grid, by which the voltage of high-speed traction power supply system is distorted. The detection method based on phase identifying principle cannot detect the voltage zero crossing time when the voltage is distorted, it will cause error during the detection process [17-18]. So, as the voltage is distorted in high-speed railway V/v wiring power supply system, this paper proposed a new detection method for three phase fundamental positive sequence voltage, it is able to avoid the detection error and delay caused by PLL hardware circuit and participate in the calculation of grid current fundamental active component. As a result, it will eliminate the compensation current detection error caused by the distorted grid voltage.

When the three-phase grid voltage are asymmetric and distorted, they can be expressed by symmetrical component method as

$$
\begin{aligned}
& u_{\mathrm{A}}=\sum_{n=1}^{+\infty} \sqrt{2} U_{n+} \sin \left(n \omega t+\phi_{n+}\right)+\sum_{n=1}^{+\infty} \sqrt{2} U_{n-} \sin \left(n \omega t+\phi_{n-}\right) \\
& u_{\mathrm{B}}=\sum_{n=1}^{+\infty} \sqrt{2} U_{n+} \sin \left[n\left(\omega t-120^{\circ}\right)+\phi_{n+}\right]+\sum_{n=1}^{+\infty} \sqrt{2} U_{n-} \sin \left[n\left(\omega t+120^{\circ}\right)+\phi_{n-}\right] \\
& u_{\mathrm{C}}=\sum_{n=1}^{+\infty} \sqrt{2} U_{n+} \sin \left[n\left(\omega t+120^{\circ}\right)+\phi_{n+}\right]+\sum_{n=1}^{+\infty} \sqrt{2} U_{n-} \sin \left[n\left(\omega t-120^{\circ}\right)+\phi_{n-}\right]
\end{aligned}
$$

Transformation matrix $\mathbf{C}_{\mathrm{abc}-\mathrm{dq}}$ is

$$
\mathbf{C}_{\mathrm{abc}-\mathrm{dq}}=\sqrt{\frac{2}{3}}\left[\begin{array}{ccc}
\sin (\omega t+\theta) & \sin \left(\omega t-120^{\circ}+\theta\right) & \sin \left(\omega t+120^{\circ}+\theta\right) \\
-\cos (\omega t+\theta) & -\cos \left(\omega t-120^{\circ}+\theta\right) & -\cos \left(\omega t+120^{\circ}+\theta\right)
\end{array}\right]
$$

Matrix $\mathbf{C}_{\mathrm{dq}-\mathrm{abc}}$ is

$$
\mathbf{C}_{\mathrm{dq}-\mathrm{abc}}=\sqrt{\frac{2}{3}}\left[\begin{array}{cc}
\sin (\omega t+\theta) & -\cos (\omega t+\theta) \\
\sin \left(\omega t-120^{\circ}+\theta\right) & -\cos \left(\omega t-120^{\circ}+\theta\right) \\
\sin \left(\omega t+120^{\circ}+\theta\right) & -\cos \left(\omega t+120^{\circ}+\theta\right)
\end{array}\right]
$$

Where $\theta$ is an arbitrary initial phase angle.

After transforming three-phase grid voltage in abc-dq coordinate, we can get system voltage in dq coordinate as follows

$$
\begin{aligned}
u_{\mathrm{d}}= & \sqrt{3} U_{1+} \cos \left(\phi_{1+}-\theta\right)-\sqrt{3} U_{1-} \cos \left(2 \omega t+\phi_{1-}+\theta\right) \mp \sum_{n=2}^{+\infty} \sqrt{3} U_{n+} \cos \left[(n \pm 1) \omega t+\phi_{n+} \pm \theta\right] \\
& \pm \sum_{n=2}^{+\infty} \sqrt{3} U_{n-} \cos \left[(n \mp 1) \omega t+\phi_{n-} \mp \theta\right] \\
u_{\mathrm{q}}= & \sqrt{3} U_{1+} \sin \left(\theta-\phi_{1+}\right)-\sqrt{3} U_{1-} \sin \left(2 \omega t+\theta+\phi_{1-}\right)-\sum_{n=2}^{+\infty} \sqrt{3} U_{n+} \sin \left[(n \pm 1) \omega t+\phi_{n+} \pm \theta\right] \\
& -\sum_{n=2}^{+\infty} \sqrt{3} U_{n-} \sin \left[(n \mp 1) \omega t+\phi_{n-} \mp \theta\right]
\end{aligned}
$$


After low-pass filtering $u_{\mathrm{d}}, u_{\mathrm{q}}$, we can get DC component $\bar{u}_{\mathrm{d}} 、 \bar{u}_{\mathrm{q}}$ respectively as follows

$\bar{u}_{\mathrm{d}}=\sqrt{3} U_{1+} \cos \left(\varphi_{1+}-\theta\right)$

$\bar{u}_{\mathrm{q}}=\sqrt{3} U_{1+} \sin \left(\theta-\varphi_{1+}\right)$

After inversing transforming formula (3) by matrix $\mathbf{C}_{\mathrm{dq}-\mathrm{abc}}$, we can get formulas as follows

$$
\begin{aligned}
& u_{\mathrm{A} 1+}=\sqrt{2} U_{1+} \sin \left(\omega t+\varphi_{1+}\right) \\
& u_{\mathrm{B} 1+}=\sqrt{2} U_{1+} \sin \left(\omega t-120^{\circ}+\varphi_{1+}\right) \\
& u_{\mathrm{C} 1+}=\sqrt{2} U_{1+} \sin \left(\omega t+120^{\circ}+\varphi_{1+}\right)
\end{aligned}
$$

They are fundamental positive sequence components of three-phase grid voltage, the detection process of fundamental positive sequence voltage is shown in figure 3.

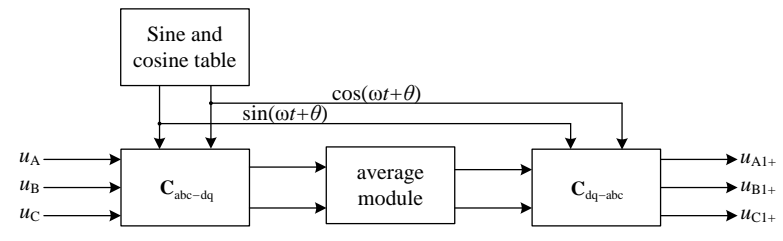

Figure 3. Diagram of Detection for Three-phase Fundamental Positive
Sequence Voltage

As the calculation result shows, the initial phase angle $\theta$ of transformation matrix does not have any effect on the detection process of fundamental positive sequence voltage, it needs only a group of $\sin (\omega t+\theta)$ and $\cos (\omega t+\theta)$ function which is produced randomly to get the grid fundamental positive sequence voltage after two transformations and a filter link, the PLL circuit is not needed to detect the voltage initial phase angle of phase A, it eliminates the detection error caused by the PLL circuit when the voltage is distorted and reduces the complexity of hardware circuit.

Via applying the calculation method mentioned above in the calculation of fundamental positive sequence voltage and compensation current, the detection error of compensation current can be effectively avoided, such kind of error occurs when the voltage is distorted.

\section{Detection Method of Compensation Current}

Under the assumption that the grid current is three-phase symmetrical and purely sinusoidal fundamental active current, the grid current $\mathrm{i}$ can be expressed as

$i=m u_{1+}$

Where $m$ is proportionality factor.

If the rms of grid fundamental positive sequence voltage and current can be expressed as $U_{1+}$ and $I$ respectively, the active power outputted by the grid can be expressed as 


$$
P_{1}=3 U_{1+} I=3 m U_{1+}{ }^{2}
$$

The rms of fundamental positive sequence voltage $U_{1+}$ can be expressed as

$$
U_{1+}^{2}=\frac{1}{3}\left(u_{\mathrm{A} 1+}^{2}+u_{\mathrm{B} 1+}^{2}+u_{\mathrm{C} 1+}^{2}\right)
$$

After putting formula (6) into formula(5), we can get the formula as follow

$$
m=P_{1} /\left(u_{\mathrm{A} 1+}^{2}+u_{\mathrm{B} 1+}^{2}+u_{\mathrm{C} 1+}^{2}\right)
$$

According to the wiring form in figure 1, the active power outputted by the grid is the active power of primary side of $\mathrm{V} / \mathrm{v}$ transformer

The active power of secondary side of V/V transformer is the active power needed by the traction supply power system, that is the sum of the required active power needed by the electric locomotives of the two supply arms, it can be expressed as

$P_{\mathrm{L}}=\frac{1}{T} \int_{0}^{T}\left(u_{\alpha} \cdot i_{\alpha \mathrm{L}}+u_{\beta} \cdot i_{\beta \mathrm{L}}\right)$

According to the energy conservation theorem of $\mathrm{V} / \mathrm{v}$ transformer primary side and secondary side, the active power of primary side and secondary side are equal, $\mathrm{P} 1=\mathrm{PL}$ 。

After putting formula (8) into formula (7), we can get a formula as follows

$$
m=\left(\frac{1}{T} \int_{0}^{T} u_{\alpha} \cdot i_{\alpha \mathrm{L}}+u_{\beta} \cdot i_{\beta \mathrm{L}}\right) /\left(u_{\mathrm{Al}+}^{2}+u_{\mathrm{B} 1+}^{2}+u_{\mathrm{Cl}+}^{2}\right)
$$

So, the command current signal that can keep the current of primary side of $\mathrm{V} / \mathrm{v}$ transformer three-phase symmetrical is

$i_{j}^{*}=m u_{j 1+}=\frac{1 / T \int_{0}^{T}\left(u_{\alpha} \cdot i_{\alpha \mathrm{L}}+u_{\beta} \cdot i_{\beta \mathrm{L}}\right) \mathrm{d} t}{\sum u_{j}^{2}} u_{j} \quad(j=\mathrm{A}, \mathrm{B}, \mathrm{C})$

Under actual conditions, losses caused by the internal switching devices and inductor resistance of power regulator will make the voltage of capacitor on the DC side drop. In order to keep the railway power regulator work properly, the grid supplies part of the active power to the power regulator while providing active power to the two supply arms, it aims at keeping the voltage of capacitor on the DC side stable.

Assuming the set value of the voltage of capacitor on the DC side is $U_{\text {ref }}$, the actual voltage of the capacitor is $U_{\mathrm{dc}}$, according to the energy conservation equation, the active power that needs to be provided to the power regulator by the grid in one period can be expressed as

$$
\Delta P=\frac{1}{2} C\left(U_{\mathrm{ref}}^{2}-U_{\mathrm{dc}}^{2}\right) / \mathrm{Ts}
$$




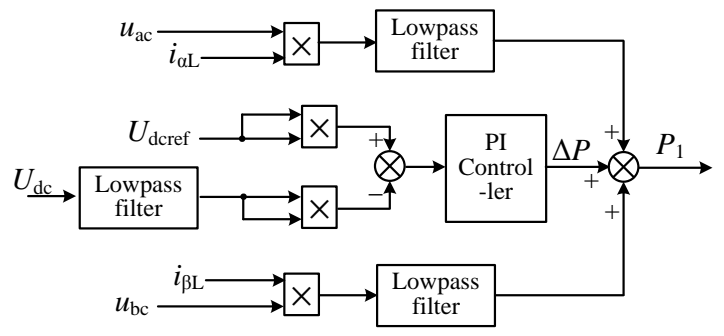

Figure 4. Calculation Diagram of Active Power on Primary side of $\mathrm{V} / \mathrm{v}$ Transformer

So, the active power P1 outputted by the grid should be equal to the sum of the active power PL and $\triangle \mathrm{P}, \mathrm{PL}$ is the active power needed by the two supply arm locomotive loads, $\Delta \mathrm{P}$ is the active power needed to keep the power regulator work properly. The calculation process of active power $\mathrm{P} 1$ is shown as figure 4.

The A, B, C three-phase command current that could keep the grid current three-phase symmetrical can be got by uniting formulas (9-11). The command current signal $i_{\alpha}^{*}, i_{\beta}^{*}$ can be got by multiplying the command current signal of phase $\mathrm{A}, \mathrm{B}$ with ratio $\mathrm{k}$ of $\mathrm{V} / \mathrm{v}$ traction transformer. The detection block diagram of command current signal of the two supply arms is shown in Figure 5.

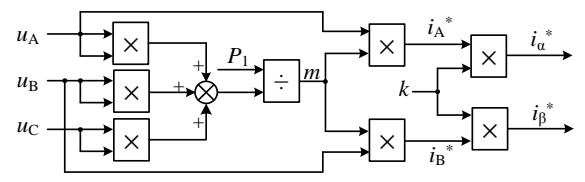

\section{Figure 5. Detection Diagram for Command Signal of the Two Supply Arms}

In order to make the control system respond fast, the hysteresis comparator method is applied into the control process to produce the pulse needed by the power regulator and then finish the comprehensive compensation that will make the grid current three-phase symmetrical.

\section{Simulation Analysis}

Table 1. System Simulation Parameters

\begin{tabular}{cc}
\hline simulation parameters & Value \\
\hline voltage of traction supply arm & $25 \mathrm{kV}$ \\
transformation ratio of step-down & $10: 1$ \\
Transformer & $1 \mathrm{mH}$ \\
output inductor $L$ & $0.05 \mathrm{~F}$ \\
capacitor C on the DC side & $4 \mathrm{kV}$ \\
given voltage on the DC side & $350 \Omega 、 100 \mathrm{mH}$ \\
un controlled rectifier load R、L & \\
of phase $\alpha$ & $200 \Omega 、 100 \mathrm{mH}$ \\
un controlled rectifier load R、L \\
of phase $\beta$
\end{tabular}


In this paper, the power regulator control system of the $220 \mathrm{kV}$ power supply system in the simulation of high-speed electrified railway is set up, and the whole system is simulated. The three-phase fundamental voltage of the grid is asymmetrical, the distorted voltage (presented by 5th,7th harmonics) are converted into two phase voltage $\alpha, \beta$ by the traction substation $\mathrm{V} / \mathrm{v}$ transformer to supply power to the two supply arms respectively. The system simulation parameters are shown as Table 1.

Distorted three-phase grid voltage is

$$
\begin{aligned}
& u_{\mathrm{A}}=240 \sqrt{2} / \sqrt{3} \sin \omega t+13 \sqrt{2} / \sqrt{3} \sin \left(5 \omega t+20^{\circ}\right)+5 \sqrt{2} / \sqrt{3} \sin \left(7 \omega t+70^{\circ}\right)(\mathrm{kV}) \\
& u_{\mathrm{B}}=190 \sqrt{2} / \sqrt{3} \sin \omega t+8 \sqrt{2} / \sqrt{3} \sin \left(5 \omega t-60^{\circ}\right)+2 \sqrt{2} / \sqrt{3} \sin \left(7 \omega t+120^{\circ}\right)(\mathrm{kV}) \\
& u_{\mathrm{C}}=230 \sqrt{2} / \sqrt{3} \sin \omega t+10 \sqrt{2} / \sqrt{3} \sin \left(5 \omega t+90^{\circ}\right)+3 \sqrt{2} / \sqrt{3} \sin \left(7 \omega t-90^{\circ}\right)(\mathrm{kV})
\end{aligned}
$$

An uncontrolled rectifier bridge load is used to simulate high-speed AC-DC electric locomotive, whose power factor is close to 1 , the locomotive load size of phase $\alpha, \beta$ are not equal, the parameters of uncontrolled rectifier load are shown as table 1. Simulation conditions are: the railway power regulator came into use to regulate the active current and compensate harmonic current of the two supply arms at $0.04 \mathrm{~s}$. The locomotive load of phase A was disconnected at $0.08 \mathrm{~s}$, the situation that there was only single-phase supply arm with locomotive was simulated. It aims at observing the moderating effects of the power regulator on the current of the two supply arms, so as to the effect of the load mutation on the entire control system.

As the detection method for three-phase fundamental positive sequence voltage of the grid proposed in this paper is applied, the fundamental positive sequence voltage can be detected fast and accurately in half period. The waveform of grid voltage and fundamental positive sequence voltage are shown in figure 6. As the figure shows, the waveform of three-phase voltage of the grid is distorted because of harmonic voltage, it's no longer ideally three-phase symmetrical voltage ,the detection method for three phase voltage proposed in this paper can extract the fundamental positive sequence voltage component fast and effectively. This method will make it participate in the calculation of grid three-phase command current and eliminate the error brought by the distorted grid voltage during the detection process of command current.

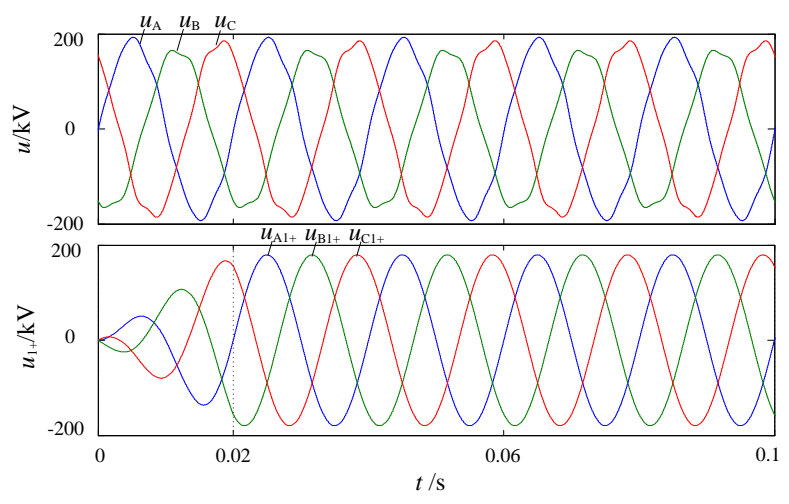

Figure 6. Waveform of Grid Voltage and Fundamental Positive Sequence Voltage 


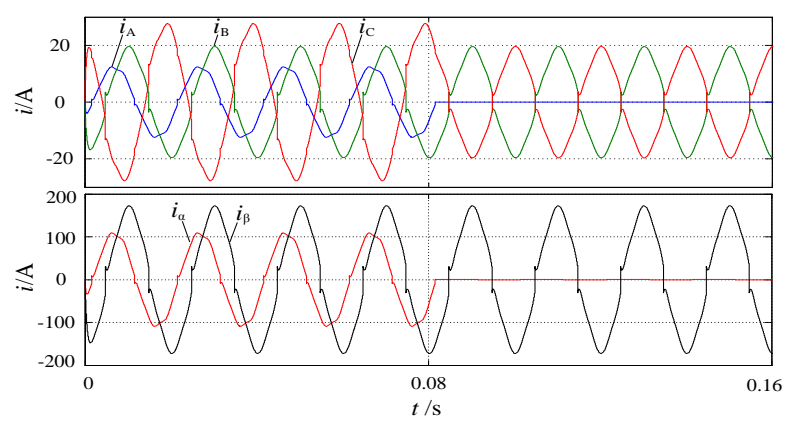

Figure 7. Waveform of Grid Three-phase Current and Two Supply Arms Current without Compensation

The waveform of grid three-phase current and two supply arm current before compensating is shown in Figure 7. As Figure 7 showed, the current of the two supply arms is unbalanced because of the random existence of the locomotives. This kind of unbalance makes the grid three-phase current asymmetrical and produces harmonic and negative sequence current, it has great influence on the safe and reliable operation of the power system.

After the power regulator was put into use, the waveform of grid three-phase current and two supply arms current were shown in Figure 8 and Figure 9 respectively. As the figures showed, no matter whether the locomotive load change abruptly or not, after the power regulator was put into use, the entire control system can respond quickly to the actual load situation and regulate the float of active component of the two supply arms current, meanwhile, the power regulator compensated the harmonic and reactive current of the supply arm effectively, as a result, current of the two supply arms were brought to balance quickly, their size are equal and there are 120 of difference in Phase. And $\alpha$-phase current leads the $\alpha$ phase supply arm fundamental positive sequence voltage $30^{\circ}, \beta$-phase current lags $\beta$-phase power arm fundamental positive sequence voltage $30^{\circ}$. Meanwhile, these two currents are in phase with the grid fundamental positive sequence voltage. As a result, the effect of negative sequence, reactive power and harmonic current on the power system was eliminated.

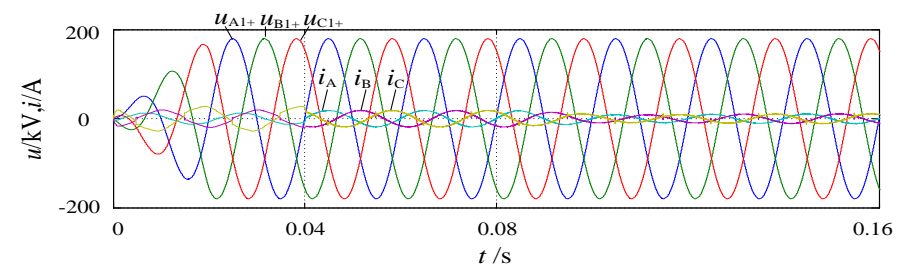

Figure 8. Waveform of Grid Fundamental Positive Sequence Voltage and Current with Compensation

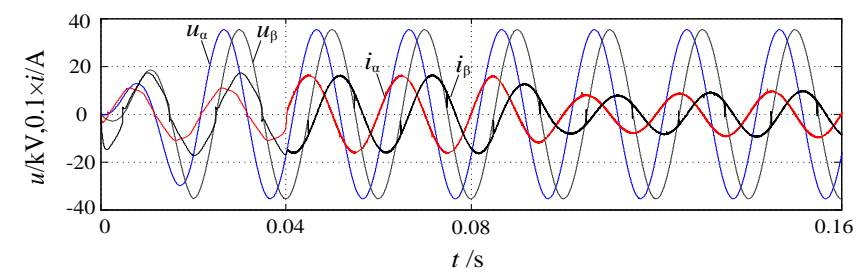

Figure 9. Waveform of Fundamental Voltage and Current for the Two Supply Arms with Compensation 


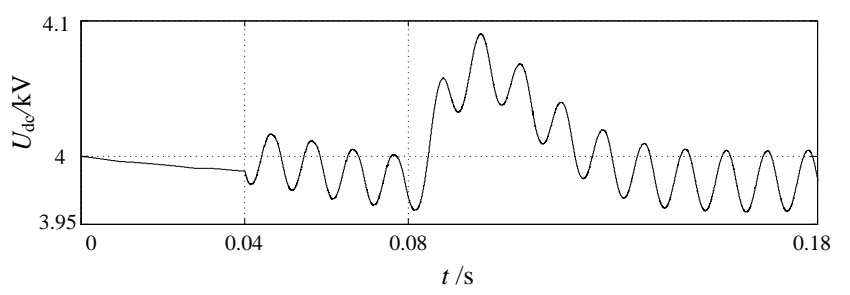

Figure 10. Capacitor Voltage on the DC Side of Power Regulator

The waveform of voltage of capacitor on the DC side of power regulator is shown in figure 10. The control method proposed in this paper can maintain the voltage of capacitor around $4 \mathrm{kV}$, and the volatility was kept around $1 \%$. Meanwhile, the control system are quite stable, the voltage of capacitor can keep stable very fast before and after the locomotive load abruptly changed. These results verified the effectiveness of the comprehensive compensation method for the power regulator of high-speed railway V/v transformer power supply system when the grid voltage is distorted.

\section{Conclusion}

1. The detection method for three-phase fundamental positive sequence voltage proposed in this paper can detect the gird fundamental positive sequence voltage component fast and accurately. This method can eliminate the voltage zero across detection error brought by the application of PLL circuit when the grid voltage is distorted. Also, it can be effectively used in the detection of three phase fundamental voltage.

2. A comprehensive compensation method is proposed for the power regulator of highspeed railway when the grid voltage is distorted. This method can eliminate the effect of negative sequence and harmonic current on the power system effectively .It is capable of realtime regulating the active current and compensation current of the two supply arms. The calculation process does not need PLL circuit, it needs only simple scalar multiplication to detect the command current for power regulator to keep the grid three-phase current symmetrical. The result of simulation verifies the effectiveness and correctness of the comprehensive compensation method for the power regulator of high-speed railway $\mathrm{V} / \mathrm{v}$ transformer power supply system proposed in this paper.

\section{Acknowledgements}

This paper is supported by the National Natural Science Foundation of China (No. 51167009).

\section{References}

[1] Y. Liu, G. Wu, H. Hua, L. Wang, D. Lu and Z. Deng, "Research on the Effects of High-speed Railway Traction Load on the Power System”, Power System Protection and Control, vol. 39, no. 18,(2011), pp. 150154.

[2] X. Zhang and Z. Li, "Research on Power Supply with 220kv and $110 \mathrm{kv}$ in Traction Substations of Electric Railways”, Power System Protection and Control, vol. 36, no. 17, (2008), pp. 13-15.

[3] H. Park, J. Han and J. Song, "A Novel Control Algorithm for Railway Power Quality Conditioner in AC Electrified Railway Systems”, Journal of International Council on Electrical Engineering, vol. 1, no. 2, (2011), pp. 145-150.

[4] C. Zeng, A. Luo, F. Ma, X. Yang and J. Wu, "A Novel Power Quality Compensation System for High-speed Railway and its Parameter Design”, Power System Technology, vol. 35, no. 10, (2011), pp. 64-69. 
[5] N. Y. Dai, "Hybrid Power Quality Conditioner for Co-phase Power Supply System in Electrified Railway", Power Electronics, IET, vol. 5, no. 7, (2012), pp. 1084-1094.

[6] L. Fang, A. Luo, X. Xu, C. Wu, H. Fang, Q. Li and W. Wang, "A Novel Power Quality Compensator for High-speed Electric Railway”, Transactions of China Electrotechnical Society, vol. 25, no. 12, (2010), pp. 167-176.

[7] Y. Mochinaga, Y. Hisamizu, M. Takeda, T. Miyashita and K. Hasuike, "Static Power Conditioner using GTO Converters for AC Electric Railway”, Power Conversion Conference, (1993), pp. 641-646.

[8] Y. Ou, Y. Zhou and Z. Guo, "A Compensation Method for Current Balance Based on Balance Transformer", Transactions of China Electrotechnical Society, vol. 22, no. 5, (2007), pp. 53-57.

[9] D. Qiu, Q. Li, F. Zhou and J. Yu, "Feed-forward Decoupling Control Strategy of DSTATCOM", Electric Power Automation Equipment, vol. 30, no. 6, (2010), pp. 36-39.

[10] Y. Xia, Q. Li, Y. Zhao and C. Xiao, "Compensation based on Instantaneous Reactive Current Detection Theory and Balance Transformer for Traction Substation”, Electric Power Automation Equipment, vol. 31, no. 9 , (2011), pp.42-45.

[11] C. Wu, A. Luo, X. Xu, F. Ma and J. Sun, "Integrative Compensation Method of Negative Phase Sequence and Harmonic for High-speed Railway Traction Supply System with V/v Transformer", Proceedings of the CSEE, vol. 30, no. 16, (2010), pp. 111-117.

[12] A. Luo, F. Ma, C. Wu, S. Qi Ding, Z. Shuai and Q.-C. Zhong, "A Dual-loop Control Strategy of Railway Static Power Regulator Under V/v Electric Traction System”, IEEE Transactions on Power Electronics, vol. 26, no. 7, (2011), pp. 2079-2091.

[13] A. Luo, C. Wu, J. Shen, Z. Shuai and F. Ma, "Railway Static Power Conditioners for High-speed Train Traction power supply systems using three-phase V/v transformers", IEEE Transactions on Power Electronics, vol. 26, no. 10, (2011), pp. 2844-2856.

[14] C. Wu, A. Luo, J. Sun, Y. Zhang and G. Wang, "A Power Quality Integrated Compensation System for Electric Railway", Transactions of China Electrotechnical Society, vol. 26, no. 10, (2011), pp. 68-76.

[15] F. Ma, A. Luo, X. Xu, H. Xiao, C. Wu and W. Wang, "A Simplified Power Conditioner based on Halfbridge Converter for High-speed Railway System”, IEEE Transactions on Industrial Electronics, vol. 60, no. 2, (2013), pp. 728-738.

[16] L. Kou, A. Luo, C. Wu and Q. Xiong, “A Novel Power Quality Compensation Device based on Two-phase Three-wire Converter for High Speed Electric Railway", Power System Technology, vol. 37, no. 1, (2013), pp. 224-229.

[17] H. Xu, W. Zhang, H. Xu, Y. He and P. Zhou, "Synchronizing Signal Detection of Fundamental Voltage Under Unbalanced and/or Distorted Grid Voltage Conditions", Automation of Electric Power Systems, vol. 36, no. 5, (2012), pp. 90-95.

[18] J. Ding, H. Zhang and X. Zhang, "An Improved Method without PLL on Harmonics Detection", Power System Protection and Control, vol. 37, no. 24, (2009), pp. 41-45.

\section{Authors}

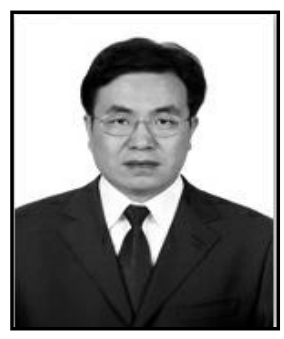

Mingxing Tian, (1968-), he is serving as a full-time professor at school of Electrical Engineering, LanZhou Jiaotong University.His research interest includes compensation for the reactive power and power quality of power system.

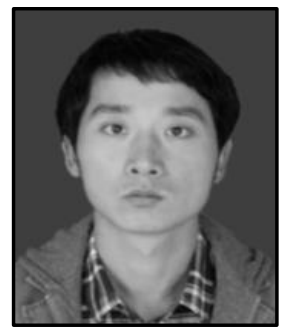

Yuqi Zhou, (1988-), he was born in Baiyin, Gansu province, China, as a master candidate, he majors in power electronics in school of Automation and Electrical Engineering, Lanzhou JiaoTong university from 2011, mainly studies the improvement of power quality. 
International Journal of Control and Automation

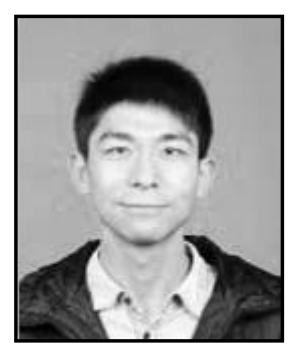

Hong Yan, (1987-), he is a master candidate in Power Electronics and Power Drives in Lanzhou Jiaotong University, China.His recent research interest is Power Electronics technology and its application in power system. 